\title{
Synthesis, Thermal Behaviour, XRD, and Luminescent Properties of Lighter Lanthanidethiodipropionate Hydrates Containing Aminogunidine as Neutral Ligand
}

\author{
S. Packiaraj, S. Govindarajan* \\ Department of Chemistry, Bharathiar University, Coimbatore, India \\ Email: srajguru1987@gmail.com, ${ }^{*}$ drsgovind@yahoo.co.in
}

Received 4 June 2014; revised 3 July 2014; accepted 30 July 2014

Copyright (C) 2014 by authors and Scientific Research Publishing Inc.

This work is licensed under the Creative Commons Attribution International License (CC BY). http://creativecommons.org/licenses/by/4.0/

\section{(c) (i) Open Access}

\begin{abstract}
Aminoguanidine lanthanide thiodipropionate hydrates of composition [ $\operatorname{Ln}(\operatorname{Agun})_{2}(\operatorname{tdp})_{3} \cdot n \mathrm{H}_{2} \mathrm{O}$ ], Agun = Aminoguanidine, $\operatorname{tdp}=$ thiodipropionic acid, where $\mathrm{Ln}=\mathrm{La}, \mathrm{Pr}$, Nd and Sm if $n=2$, have been prepared and characterized by physic-chemical techniques.
\end{abstract}

Keywords

Aminoguanidine, 3,3-Thiodipropionic Acid, Rare Earth Metals, Spectral and Thermal Studies

\section{Introduction}

Rapidly, the research activities concerning metal organic frameworks (MOF) based on the lanthanide family are expanding, not only for their fascinating coordination geometry and versatile architecture, but also for their potential utilization as luminescent and sensory materials [1]-[3]. Because of the high coordination nature, controlling the overall frameworks of lanthanide-based coordination polymers, undoubtedly, is a challenge. However, this provides an opportunity for the construction of various MOF with different topologies and specific properties. The coordination compounds containing, aminoguanidine acts as a monodentate, bidentate as well as neutral ligand in many metal complexes. The coordination chemistry of aminoguanidine has been described for few transition metals [4] [5]. This has been established by single crystal X-ray studies on Agun containing complexes with both pt (II) and pd (II) [6]. There has been a significant amount of interest in the chemistry of rare-earth

${ }^{*}$ Corresponding author.

How to cite this paper: Packiaraj, S. and Govindarajan, S. (2014) Synthesis, Thermal Behaviour, XRD, and Luminescent Properties of Lighter Lanthanidethiodipropionate Hydrates Containing Aminogunidine as Neutral Ligand. Open Journal of Inorganic Chemistry, 4, 41-49. http://dx.doi.org/10.4236/ojic.2014.43006 
complexes of aminoguanidine with carboxylic acid. The thermal reactivity of aminoguanidine in the complexes is also curious due to its fueling nature. Thus, a variety of metal aminoguanidine complexes has been prepared and investigated by inorganic chemists as coordination compounds.

Our recent interest in Agun began with preparation and thermal degradation of metal complexes of sulphur containing heteroaliphaticdicarboxylic acid, particularly thiodipropionic acid, $\mathrm{H}_{2} \mathrm{~S}\left(\mathrm{CH}_{2} \mathrm{CH}_{2} \mathrm{COO}\right)_{2}$. Though several types of binding ability of thiodipropionic acid with transition metals have been demonstrated including spectral studies [7], there is no report available up to now on the lanthanide complexes of the above acid. In this paper, we report for the first time the synthetical, spectral and thermal studies on trivalent lighter rare-earth complexes of thiodipropionic acid with aminoguanidine.

\section{Experimental}

\subsection{General Remarks}

All the materials were reagent grade, obtained from commercial sources and used without purification. Elemental analyses were performed on a Vario-EC III analytical instrument. The melting points were obtained with LABINDIA-Visual melting range apparatus and were uncorrected. IR spectra in the $4000-400 \mathrm{~cm}^{-1}$ range were measured with a JASCO-320 FT-IR spectrometer using KBr pellet technique. Thermal analyses (under Nitrogenated atmosphere, heating rate of $10^{\circ} \mathrm{C} / \mathrm{min}$ ) were carried out in a Perkin-Elmer SII apparatus. The absorption spectra were recorded on a Perkin-Elmer UV-Vis spectrophotometer, JASCO-FP 630. The XRD spectra were recorded on a Bruker AXS D8 advanced X-ray diffractometer using Cu-k $\alpha$ radiation with nickel filter. Photoluminescence (PL) spectra were obtained on a JASCO-FP 6600 spectroflurometer. The excitation and emission spectra were recorded at ambient temperature.

\subsection{Preparation of [Ln(Agun) $\left.)_{2}(\operatorname{tdp})_{3} \cdot \mathrm{nH}_{2} \mathrm{O}\right]$}

The respective metal oxides (e.g., $0.163 \mathrm{~g}$ of $\mathrm{La}_{2} \mathrm{O}_{3} 0.001 \mathrm{~mol}$ ) were dissolved in a $2 \mathrm{~N} \cdot \mathrm{HNO}_{3}$ and evaporated to dryness. To this residue, $30 \mathrm{~mL}$ of distilled water was added. An aqueous solution $(25 \mathrm{~mL})$ of aminoguanidine bicarbonate $(0.004 \mathrm{~mol}, 0.544 \mathrm{~g})$ was neutralized with thiodipropinic acid $(0.004 \mathrm{~mol}, 0.712 \mathrm{~g})$. To this ligand solution was added slowly to metal nitrate solution with constant stirring. To dissolve the precipitate and to monitor the $\mathrm{pH}, 2$ or 3 drops of $2 \mathrm{~N} \cdot \mathrm{HNO}_{3}$ was added. The resulting solution of $\mathrm{pH} 4-6$ was concentrated on a water bath to one fourth of its volume. During evaporation, the polycrystalline solids were obtained and which was kept aside at room temperature for a day. The next day, the product was separated out and washed with cold water or ether and air dried. Physico-chemical techniques are the same as described [8].

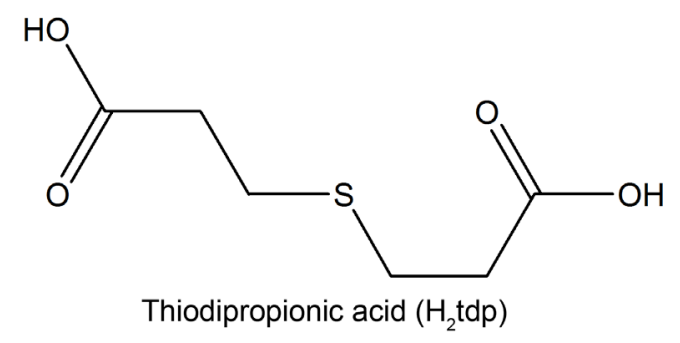

All the compounds are obtained poly crystalline solids, which are stable in air and insensitive to light. They are soluble in water and insoluble in common organic solvents like ethanol, acetone and chloroform.

The analytical data of the complexes are compatible with the proposed composition for the complexes (Table 1). The general reaction for the formation of the aminoguanidine lanthanide thiodipropionate hydrates may be written as follows.

$$
\mathrm{Ln}\left(\mathrm{NO}_{3}\right)_{3} \cdot 6 \mathrm{H}_{2} \mathrm{O}+\text { Agun }+\mathrm{H}_{2} \mathrm{tdp} \rightarrow\left[(\text { Agun })_{2} \mathrm{Ln}(\text { tdp })_{3} \cdot n\left(\mathrm{H}_{2} \mathrm{O}\right)\right]
$$

where, $\mathrm{Ln}=\mathrm{La}, \mathrm{Pr}, \mathrm{Nd}$ and Sm; if $n=2$.

Further, it is observed that the 1:4:4 ratio of lanthanide nitrate, thidipropionic acid and aminoguanidine bicarbonate, respectively, did not yield any desired product, instead only lanthanide thiodipropionate were obtained. 
Table 1. The analytical data of the complexes are compatible with the proposed composition for the complexes.

\begin{tabular}{cccccccccc}
\hline \multirow{2}{*}{ Compound } & mpt/dpt $\left({ }^{\circ} \mathrm{C}\right)$ & Colour & $\begin{array}{c}\text { Molecular } \\
\text { weight }\end{array}$ & & \multicolumn{7}{c}{ (Found calculated) \% } \\
\cline { 8 - 10 } & & & & Hydrazine & Metal & Carbon & Hydrogen & Nitrogen & Sulphur \\
\hline $\mathrm{H}_{2} \mathrm{tdp}$ & $139(134 \mathrm{~d})^{*}$ & White & 178 & - & - & $39.88(40.35)$ & $5.34(5.61)$ & - & $17.50(17.98)$ \\
$\mathrm{H}_{2}$ Agun $\cdot \mathrm{CO}_{3}$ & $169(172 \mathrm{~d})^{*}$ & White & 136 & $23.45(23.53)$ & - & $17.54(17.64)$ & $5.46(5.88)$ & $40.95(41.18)$ & - \\
$\mathrm{La}$ & 110 & White & 1067 & $6.20(6.42)$ & $28.10(27.91)$ & $23.54(23.61)$ & $4.15(4.31)$ & $15.45(15.75)$ & $8.85(8.99)$ \\
$\mathrm{Pr}$ & 180 & Green & 1069 & $6.15(6.64)$ & $30.10(29.25)$ & $23.45(23.57)$ & $4.08(4.30)$ & $15.86(15.72)$ & $8.78(8.98)$ \\
$\mathrm{Nd}$ & 170 & Violet & 1072 & $7.30(6.36)$ & $29.50(28.70)$ & $23.35(23.50)$ & $4.15(4.29)$ & $15.75(15.67)$ & $8.82(8.95)$ \\
$\mathrm{Sm}$ & 120 & yellow & 1078 & $6.65(6.50)$ & $30.90(30.56)$ & $23.45(23.37)$ & $4.10(4.27)$ & $15.63(15.58)$ & $8.48(8.90)$ \\
\hline
\end{tabular}

*Reported value; d: decomposition temperature.

\subsection{Infrared Spectra of the Complexes}

The N-N stretching frequency of the free aminoguanidine is known to occur in the region $1113 \mathrm{~cm}^{-1}$ [9]. The N-N stretching frequencies (Table 2) observed in the range $1110-1139 \mathrm{~cm}^{-1}$ is an ample evidence for the presence of coordinated aminoguanidine as a neutral in the complexes. The carbonyl stretching of free acid is observed at $1696 \mathrm{~cm}^{-1}$. In all the complexes the asymmetric and symmetric stretching frequencies of the carboxylate ions are seen in the range $1560-1540 \mathrm{~cm}^{-1}$ and $1460-1440 \mathrm{~cm}^{-1}$, respectively, with an average separation of $\left(\Delta \mathrm{v}=\mathrm{v}_{\text {asym }}-\mathrm{v}_{\text {sym }}\right) 100 \mathrm{~cm}^{-1}$ indicating the bidentate coordination of both carboxylate groups [10] in the dianion. All the complexes exhibit a strong band in the region of $650-760 \mathrm{~cm}^{-1}$ due to C-S stretching of the thioether linkage. All the compounds exhibit strong bands in the range of $3460-3430 \mathrm{~cm}^{-1}$ due to $\mathrm{O}-\mathrm{H}$ stretching, confirming the presence of water molecules [10].

\subsection{Electronic Spectra of the Complexes}

The absorption spectra of the Pr, Nd and Sm were recorded and compared with the data for the corresponding aqua-ions. The spectral profiles of the complexes show not only shifts in positions, but also changes in intensity compared to those of the aqua-ions (Figure 1), i.e., the energies at which the various bands appear are lower. This red shift, which is measure of metal-ligand covalent binding, has been ascribed to the nephelsauxetic (cloud expanding) effect [11]. The absorption band associated with nearly degenerate ${ }^{4} \mathrm{I}_{9 / 2} \cdot{ }^{2} \mathrm{G}_{7 / 2},{ }^{4} \mathrm{G}_{5 / 2}$ transition of $\mathrm{Nd}^{3+}$ is known to exhibit strong hypersensitivity behavior [12], making it especially suitable for probing the coordination environment around the $\mathrm{Nd}^{3+}$ ion.

All the parameters $\beta, b^{1 / 2}, \% \delta$ and $\eta$ values (Table 2) are comparable with those of oxygen-donor ligands such as oxalate and phthalate [12]-[14]. The $\beta$ values obtained in the in series are around unity showing an almost completely ionic character for the $\mathrm{Ln}^{3+}$ ligand interaction. The spectral profiles present $\mathrm{Nd}^{3+}$ complex resembles those of the nine-coordinated complexes [15] [16].

\subsection{Thermogravimetric Analysis}

The simultaneous TG-DTA results of the La, Pr, Nd and Sm complexes are similar and all of them under go three stages of weight loss (Table 3) upon heating. The first stage, which occurs in the range $80^{\circ} \mathrm{C}-200^{\circ} \mathrm{C}$ is attributed to the loss of two water molecules. In DTA this loss of water is observed as an endotherm around $200^{\circ} \mathrm{C}$ and such slightly high temperature of dehydration confirming the presence of two coordinated water molecules in the complexes. This loss of water is supported by the weight loss in TG. The presence of lattice and coordinated water molecules has been reported [16]. After this the anhydrous compounds loss aminoguanidine exothermically around $200^{\circ} \mathrm{C}-380^{\circ} \mathrm{C}$ to form $\mathrm{Ln}_{2}(\mathrm{tdp})_{3}$ as an intermediate. In DTA, this loss of two molecules each of aminoguanidine seen as a broad exotherm around $380^{\circ} \mathrm{C}$. In the final step, the isomeric thiodipropionates of metal decompose exothermically in the range $380^{\circ} \mathrm{C}-800^{\circ} \mathrm{C}$ to give the respective $\mathrm{Ln}_{2} \mathrm{~S}_{3}$ as the final residue.

As a representative example, the decomposition reaction of the lanthanum compound, in air are given below on the basis of the mass losses in the TG curve. 
Table 2. All the parameters $\beta, b^{1 / 2}, \% \delta$ and $\eta$ values.

\begin{tabular}{|c|c|c|c|c|c|c|c|c|c|}
\hline \multirow{2}{*}{ Compound } & \multicolumn{7}{|c|}{ Infrared spectral data $\left(\mathrm{cm}^{-1}\right)$} & \multicolumn{2}{|c|}{ Electronic spectra } \\
\hline & $\gamma_{\mathrm{O}-\mathrm{H} \text { Str. }}$ & $\gamma_{\mathrm{N}-\mathrm{H} \text { Str }}$ & $\gamma_{\mathrm{C}-\mathrm{H} \text { Str }} \cdot$ & $\gamma \mathrm{oco}_{\text {Asy.Str. }}$ & $\gamma \mathrm{oco}_{\mathrm{str}}$. & $\gamma_{\mathrm{N}-\mathrm{N} \text { Str. }}$ & $\gamma_{\mathrm{C}-\mathrm{S} \text { Str }} \cdot$ & Band max $\left(\mathrm{cm}^{-1}\right)$ & Parameters \\
\hline $\mathrm{H}_{2} \mathrm{tdp}$ & 3028 & - & 2950 & 1696 & - & - & 926 & - & - \\
\hline $\mathrm{H}_{2}$ Agun $\cdot \mathrm{CO}_{3}$ & - & 3130 & - & - & 1391 & 1113 & - & - & - \\
\hline $\mathrm{La}$ & 3353 & 3240 & 2925 & 1536 & 1436 & 1110 & 948 & - & - \\
\hline $\operatorname{Pr}$ & 3454 & 3250 & 2924 & 1530 & 1418 & 1115 & 947 & $\begin{array}{l}22,522 \\
21,322 \\
20,449 \\
17,094\end{array}$ & $\begin{array}{c}\beta=0.9996 \\
b^{1 / 2}=0.0142 \\
\% \delta=0.0401 \\
\eta=0.0002\end{array}$ \\
\hline Nd & 3460 & 3250 & 2924 & 1530 & 1419 & 1134 & 947 & $\begin{array}{l}22,271 \\
19,305 \\
19,157 \\
13,495 \\
12,563 \\
11,547\end{array}$ & $\begin{array}{c}\beta=0.9989 \\
b^{1 / 2}=0.0235 \\
\% \delta=0.1101 \\
\eta=0.0006\end{array}$ \\
\hline Sm & 3471 & 3085 & 2925 & 1537 & 1428 & 1139 & 950 & $\begin{array}{l}27,472 \\
26,738 \\
24,875 \\
24,038 \\
21,598 \\
20,920\end{array}$ & $\begin{array}{c}\beta=0.9987 \\
b^{1 / 2}=0.0255 \\
\% \delta=0.1302 \\
\eta=0.0006\end{array}$ \\
\hline
\end{tabular}

Table 3. The simultaneous TG-DTA results of the La, Pr, Nd and Sm complexes are similar and all of them under go three stages of weight loss upon heating.

\begin{tabular}{|c|c|c|c|c|c|}
\hline \multirow{3}{*}{ Compound } & \multirow{3}{*}{ DTA Peak Temp. $\left({ }^{\circ} \mathrm{C}\right)$} & \multicolumn{3}{|c|}{ Thermogravimetry } & \multirow{3}{*}{$\begin{array}{c}\text { Possible } \\
\text { Intermediates/End } \\
\text { Products }\end{array}$} \\
\hline & & \multirow{2}{*}{ Temp. Range $/{ }^{\circ} \mathrm{C}$} & \multicolumn{2}{|c|}{ Mass Loss (\%) } & \\
\hline & & & Obsd. & Calcd. & \\
\hline \multirow[t]{2}{*}{$\mathrm{H}_{2} \mathrm{Agun} \cdot \mathrm{CO}_{3}$} & $\left.\begin{array}{l}(+) 135 \\
(+) 175\end{array}\right\}$ & $90-180$ & 69.00 & 69.12 & Formation of $\mathrm{NH}=\mathrm{C}=\mathrm{NH}$ \\
\hline & $(-) 595$ & $180-600$ & 100 & 100 & Complete Decomposition \\
\hline \multirow[t]{3}{*}{$\mathrm{La}_{2}(\mathrm{tdp})_{3}(\text { Agun })_{2} \cdot 2 \mathrm{H}_{2} \mathrm{O}$} & $(+) 170$ & $80-200$ & 3.60 & 4.04 & $\mathrm{La}_{2}(\mathrm{tdp})_{3}$ (Agun) $)_{2}$ \\
\hline & $(-) 370$ & $200-350$ & 18.70 & 20.35 & $\mathrm{La}_{2}(\mathrm{tdp})_{3}$ \\
\hline & $(-) 610$ & $350-750$ & 62.00 & 62.45 & $\mathrm{La}_{2} \mathrm{~S}_{3}$ \\
\hline \multirow[t]{3}{*}{$\mathrm{Pr}_{2}(\mathrm{tdp})_{3}(\text { Agun })_{2} \cdot 2 \mathrm{H}_{2} \mathrm{O}$} & $(+) 200$ & $90-250$ & 3.70 & 4.00 & $\operatorname{Pr}_{2}(\text { tdp })_{3}$ (Agun) $)_{2}$ \\
\hline & $(-) 360$ & $250-400$ & 19.30 & 20.04 & $\operatorname{Pr}_{2}(\mathrm{tdp})_{3}$ \\
\hline & $(-) 600$ & $400-750$ & 53.40 & 60.79 & $\mathrm{Pr}_{2} \mathrm{~S}_{3}$ \\
\hline \multirow[t]{3}{*}{$\mathrm{Nd}_{2}(\mathrm{tdp})_{3}(\text { Agun })_{2} \cdot 2 \mathrm{H}_{2} \mathrm{O}$} & $(+) 190$ & $90-250$ & 3.60 & 4.00 & $\mathrm{Nd}_{2}(\mathrm{tdp})_{3}(\text { Agun })_{2}$ \\
\hline & $(-) 360$ & $250-400$ & 18.50 & 19.50 & $\mathrm{Nd}_{2}(\mathrm{tdp})_{3}$ \\
\hline & $(-) 620$ & $400-750$ & 54.50 & 61.77 & $\mathrm{Nd}_{2} \mathrm{~S}_{3}$ \\
\hline \multirow[t]{3}{*}{$\mathrm{Sm}_{2}(\mathrm{tdp})_{3}(\text { Agun })_{2} \cdot 2 \mathrm{H}_{2} \mathrm{O}$} & $(+) 190$ & $90-250$ & 3.60 & 4.00 & $\mathrm{Sm}_{2}(\mathrm{tdp})_{3}(\text { Agun })_{2}$ \\
\hline & $(-) 360$ & $250-400$ & 16.50 & 17.50 & $\mathrm{Sm}_{2}(\mathrm{tdp})_{3}$ \\
\hline & $(-) 580$ & $400-750$ & 55.60 & 61.77 & $\mathrm{Sm}_{2} \mathrm{~S}_{3}$ \\
\hline
\end{tabular}



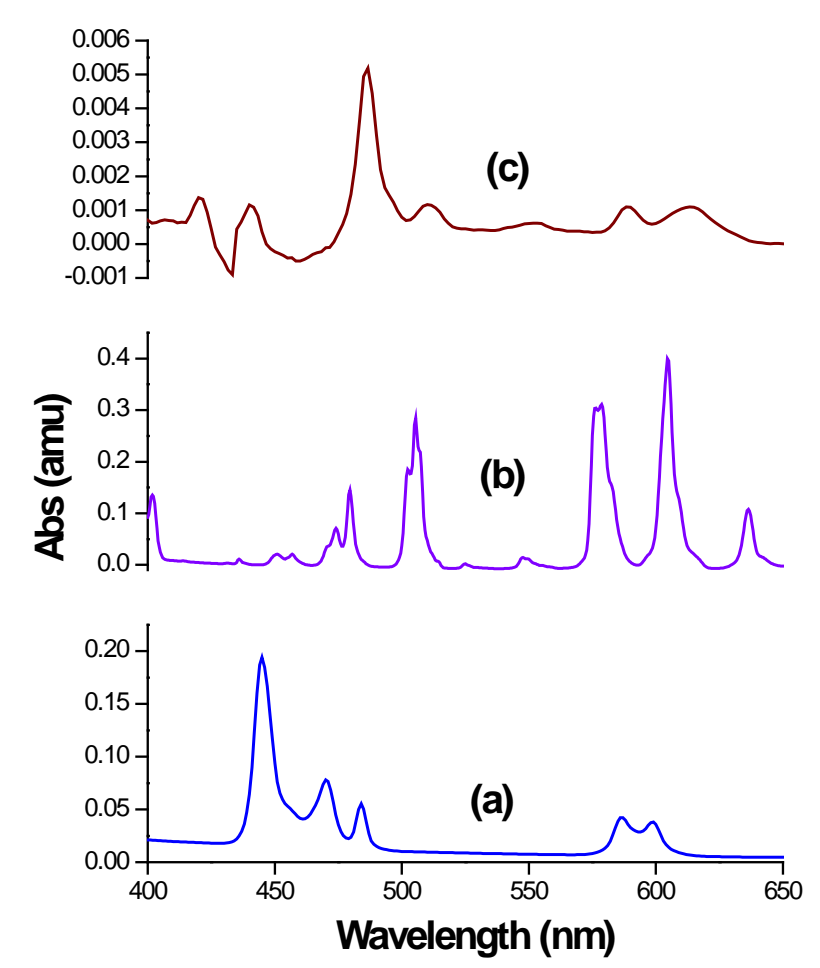

\section{Figure 1. Electronic spectra of (a) $\left[\mathrm{Pr}_{2}(\mathrm{tdp})_{3}(\mathrm{Agun})_{2} \cdot 2 \mathrm{H}_{2} \mathrm{O}\right]$; (b)} $\left.\left[\mathrm{Nd}_{2}(\mathrm{tdp})_{3} \text { (Agun) }\right)_{2} \cdot 2 \mathrm{H}_{2} \mathrm{O}\right] ;$ (c) $\left[\mathrm{Sm}_{2}(\mathrm{tdp})_{3}(\text { Agun })_{2} \cdot 2 \mathrm{H}_{2} \mathrm{O}\right]$.

The simultaneous TG-DTA of the La, Pr, Nd, and Sm compounds are shown in Figure 2. Our effort to isolate the intermediates was unsuccessful due to their continuous decomposition as evident from the TG. Hence, the probable intermediates have been assigned based on the calculated mass losses.

$$
\begin{gathered}
{\left[(\text { Agun })_{2} \mathrm{Ln}_{2}(\mathrm{tdp})_{3} \cdot\left(\mathrm{H}_{2} \mathrm{O}\right)_{2}\right] \underset{(\mathrm{Endo})}{\stackrel{80-200^{\circ} \mathrm{C}}{\longrightarrow}}\left[(\text { Agun })_{2} \mathrm{Ln}_{2}(\mathrm{tdp})_{3}\right]+\mathrm{H}_{2} \mathrm{O}} \\
{\left[(\text { Agun })_{2} \mathrm{Ln}_{2}(\mathrm{tdp})_{3}\right] \underset{(\mathrm{Exo})}{\stackrel{200-30^{\circ} \mathrm{C}}{\longrightarrow}}\left[\mathrm{Ln}_{2}(\text { tdp })_{3}\right]+2 \text { Agun }} \\
{\left[\mathrm{Ln}_{2}(\mathrm{tdp})_{3}\right] \stackrel{350-750^{\circ} \mathrm{C}}{(\mathrm{Exo})} \mathrm{Ln}_{2} \mathrm{~S}_{3}+\mathrm{H}_{2} \mathrm{O}+\mathrm{CO}_{2}}
\end{gathered}
$$

where $\mathrm{Ln}=\mathrm{La}$, Pr, Nd and Sm.

\subsection{Powder X-Ray Pattern of the Complexes}

The X-ray powder diffraction patterns for the complexes are shown in Figure 3. From the patterns, it is evident that the La, Pr, Nd and Sm complexes are isostructural. The results IR and thermo analytical studies are in accordance with these isomorphism structural groups.

\subsection{Photoluminescence Properties}

Lanthanide luminescence is demonstrated to be very sensitive to local environments around the lanthanide center [17]. Figure 4 shows the absorption spectra cover the wavelength range in the visible area. The luminescent properties of the three compounds were measured at room temperature. The Ex. Slit and Em. Slit are 2.5 and 5 $\mathrm{nm}$ respectively. The shape of UV absorption spectrum and excitation spectrum is basically similar, in addition to the different spectral intensity. The optimum excitation wavelength is around 400 to $590 \mathrm{~nm}$ for complexes (a) and (b), respectively, which is mainly derived from the $\pi-\pi$ transition absorption of ligand [18].

The praseodymium complex shows the light emission upon excitation at $589 \mathrm{~nm}$. The characteristic luminescent band of the PrIII complex has been recorded at $652 \mathrm{~nm}$, which can be attributed ${ }^{3} \mathrm{H}_{4} \cdot{ }^{1} \mathrm{D}_{\mathrm{J}},{ }^{3} \mathrm{P}_{\mathrm{J}}(\mathrm{J}=0,1,2)$ shown in Table 2. 


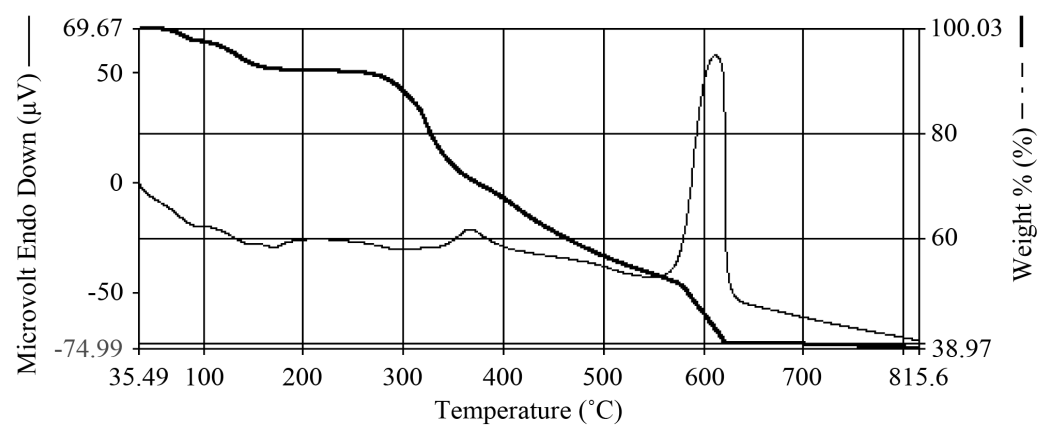

(a)

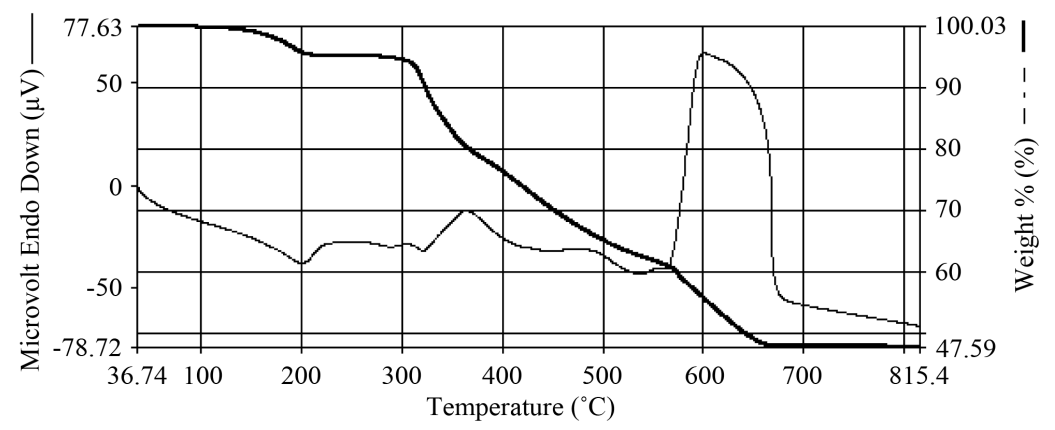

(b)

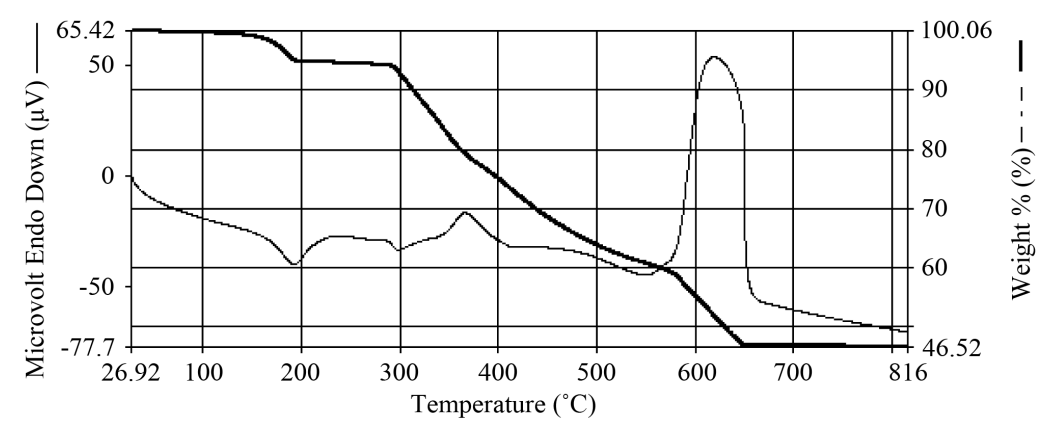

(c)

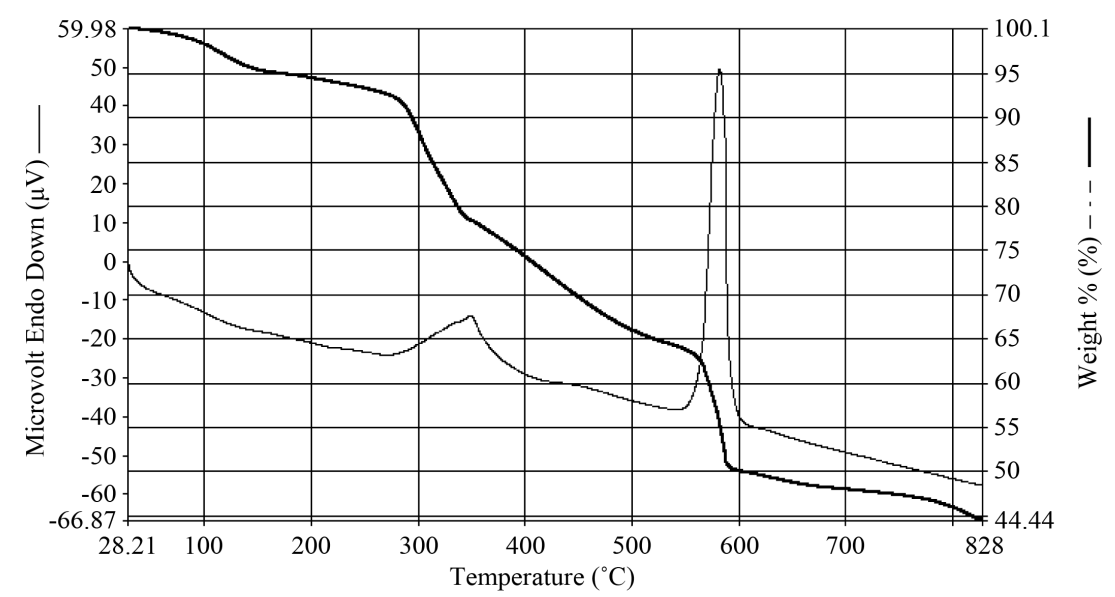

(d)

Figure 2. Simultaneous TG-DTA of: (a) $\left[\mathrm{La}_{2}(\mathrm{tdp})_{3}(\mathrm{Agun})_{2} \cdot 2 \mathrm{H}_{2} \mathrm{O}\right]$; (b) $\left[\mathrm{Pr}_{2}(\mathrm{tdp})_{3}(\mathrm{Agun})_{2} \cdot 2 \mathrm{H}_{2} \mathrm{O}\right]$; (c) $\left[\mathrm{Nd}_{2}(\mathrm{tdp})_{3}(\text { Agun })_{2} \cdot 2 \mathrm{H}_{2} \mathrm{O}\right] ;$ (d) $\left[\mathrm{Sm}_{2}(\mathrm{tdp})_{3}(\text { Agun })_{2} \cdot 2 \mathrm{H}_{2} \mathrm{O}\right]$. 

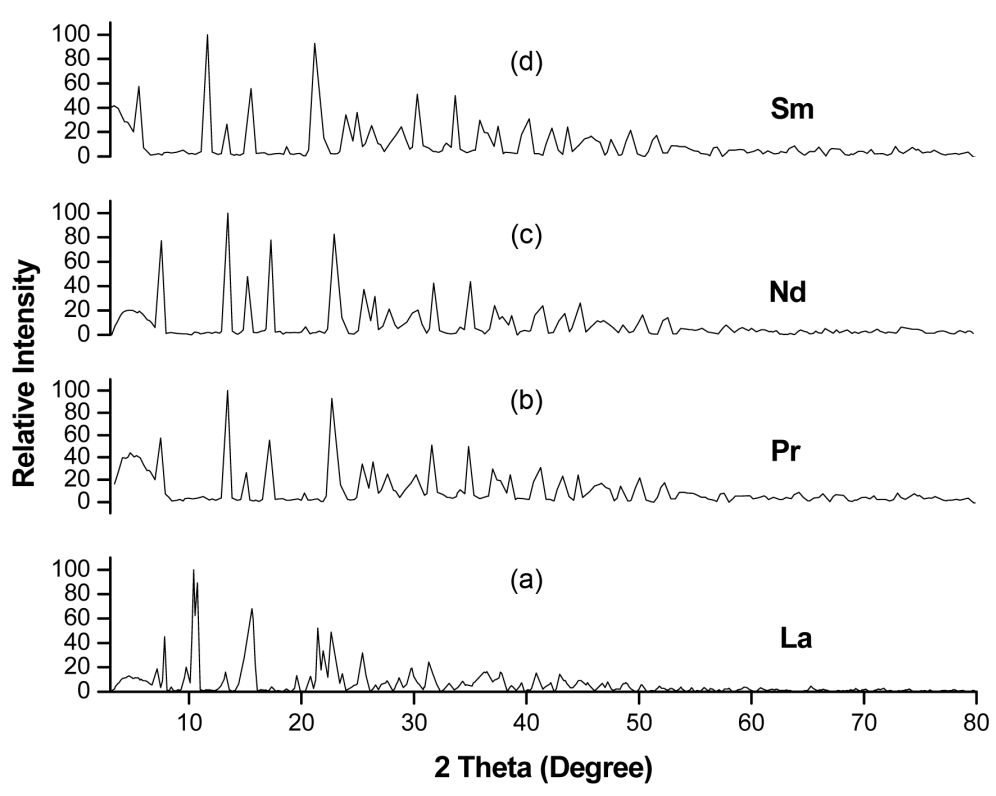

Figure 3. X-ray powder diffraction patterns of (a) $\left[\mathrm{La}_{2}(\mathrm{tdp})_{3}(\text { Agun })_{2} \cdot 2 \mathrm{H}_{2} \mathrm{O}\right]$; (b)

$\left.\left[\mathrm{Pr}_{2}(\mathrm{tdp})_{3} \text { (Agun) }\right)_{2} \cdot 2 \mathrm{H}_{2} \mathrm{O}\right] ;$ (c) $\left[\mathrm{Nd}_{2}(\mathrm{tdp})_{3}(\text { Agun })_{2} \cdot 2 \mathrm{H}_{2} \mathrm{O}\right] ;$ (d) $\left[\mathrm{Sm}_{2}(\mathrm{tdp})_{3}(\text { Agun })_{2} \cdot 2 \mathrm{H}_{2} \mathrm{O}\right]$.

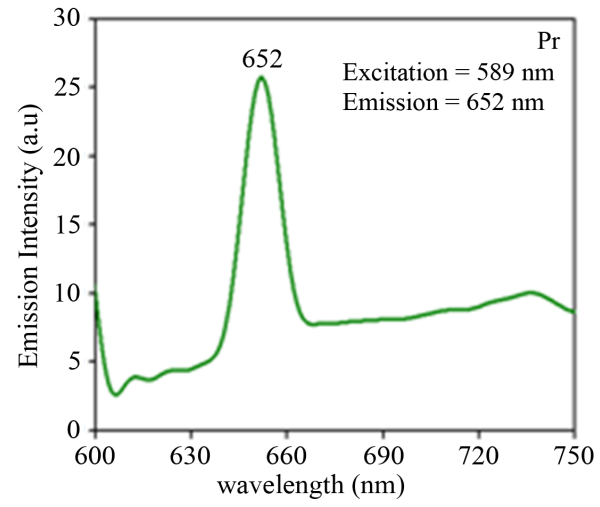

(a)

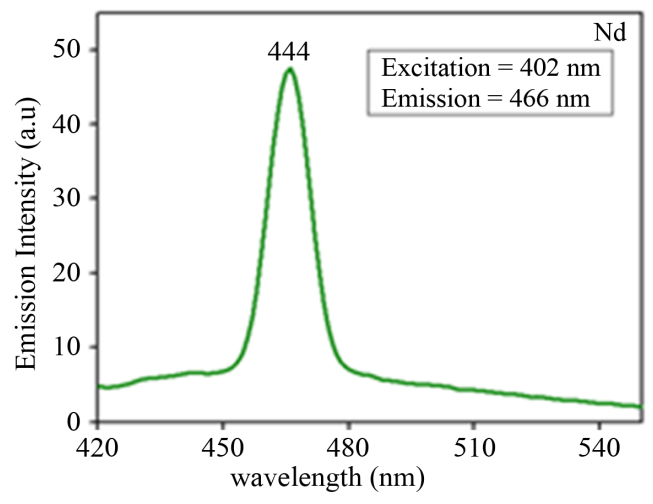

(b)

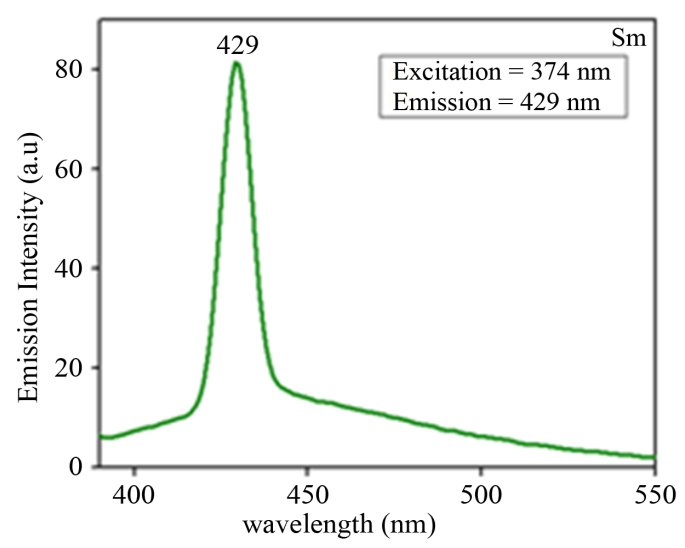

(c)

Figure 4. Photoluminescence spectra of (a) $\left[\mathrm{Pr}_{2}(\mathrm{tdp})_{3}(\text { Agun })_{2} \cdot 2 \mathrm{H}_{2} \mathrm{O}\right]$; (b) $\left[\mathrm{Nd}_{2}(\mathrm{tdp})_{3}(\text { Agun })_{2} \cdot 2 \mathrm{H}_{2} \mathrm{O}\right]$; (c) $\left[\mathrm{Sm}_{2}(\mathrm{tdp})_{3}(\text { Agun })_{2} \cdot 2 \mathrm{H}_{2} \mathrm{O}\right]$. 
The neodymium complex shows the light emission upon excitation at $427 \mathrm{~nm}$ and $577 \mathrm{~nm}$ at room temperature. This displays photoluminescence at $499 \mathrm{~nm}, 638 \mathrm{~nm}$ respectively, which can be attributed to ${ }^{4} \mathrm{I}_{9 / 2}{ }^{4} \mathrm{~F}_{\mathrm{J}},{ }^{2} \mathrm{H}_{\mathrm{J}}$, ${ }^{4} \mathrm{G}_{\mathrm{J}} \quad(\mathrm{J}=5 / 2,7 / 2,9 / 2)$ shown in Table 2, transitions takes place.

The samarium complex shows the light emission upon excitation at $402 \mathrm{~nm}$ at room temperature. The luminescent band of the SmIII complex is observed at $466 \mathrm{~nm}$, which can be attributed to ${ }^{4} \mathrm{G}_{5 / 2} \cdot{ }^{6} \mathrm{H}_{\mathrm{J}}$ $(\mathrm{J}=5 / 2,7 / 2,9 / 2)$ transition.

These characteristic emission bands indicate that the ligand to metal transfer is moderately efficient under the experimental conditions used. These characteristic emission bands indicate that the ligand-to-metal energy transfer is moderately efficient under the experimental conditions used [19].

\section{Conclusions}

Based on the evidences drawn from the analytical, spectral and thermal properties, it is reasonable to propose a structure for the complexes in which aminoguanidine acts as a neutral ligand inside the coordination sphere. Further, in most of the metal thiodipropionate carboxylates [7], it has been proved crystallographically that the thiodipropinic carboxylate moiety is bridging the two metal ions by chelation through carboxylate oxygen atom leading to two dimensional chain structures. Thus, it is concluded that in these complexes also each thiodipropionic carboxylate moiety is acting as a pentadentate bridging ligand leading to two dimensional polymeric structures. The ninth coordination is being satisfied by a water oxygen atom.

Further, the infrared spectral results and the poor solubility of these compounds in polar and non-polar solvents are in contermity with the polymeric structure [20]. These complexes may be used as precursors to fine particle metal sulphide due to their low temperature of decomposition. Photoluminescence measurements indicate that the praseodymium, neodymium compound was yellow emitters, and the samarium complex shows orange light emission in the solid state at room temperature. This work may offer a feasible strategy for rational combinations of different connectivities within a net structure, and may also enrich the family of lanthanide chemistry.

\section{References}

[1] Wang, Y.-L., Yuan, D.-Q., Bi, W.-H., Li, X., Li, X.-J., Li, F. and Cao, R. (2005) Syntheses and Characterizations of Two 3D Cobalt-Organic Frameworks from 2D Honeycomb Building Blocks. Crystal Growth Design, 5, 1849-1885. http://dx.doi.org/10.1021/cg0501128

[2] Zhu, X.D., Lu, J., Li, X.J., Gao, S.Y., Li, G.L. and Cao, R. (2008) Syntheses, Structures, Near-Infrared, and Visible Luminescence of Lanthanide-Organic Frameworks with Flexible Macrocyclic Polyamine Ligands. Crystal Growth Design, 8, 1897-1901. http://dx.doi.org/10.1021/cg701098t

[3] Yuan, F.G., Liu, X.J. and Zhang, Y. (2005) Reaction of $\left(\mathrm{Ph}_{2} \mathrm{~N}\right)_{2} \mathrm{Sm}(\mathrm{THF})_{4}$ with Azobenzene: Synthesis, X-Ray Structure and Catalytic Behavior of $\left[\left(\mathrm{Ph}_{2} \mathrm{~N}\right)(\mathrm{DME}) \mathrm{Sm}\right]_{2}\left(\mu-\eta^{2}: \eta^{2}-\mathrm{N}_{2} \mathrm{Ph}_{2}\right)_{2}$. Chinese Journal of Chemistry, 23, 749-752. http://dx.doi.org/10.1002/cjoc.200590749

[4] Boldyrev, V.V., Tukhtaev, R.K., Gavrilov, A.I., Larionov, S.V., Savel'eva, Z.A. and Lavrenova, L.G. (1998) Combustion of Nickel and Copper Nitrate Complexes of Hydrazine Derivatives as a Method for Manufacturing Fine-Grained and Porous Metals. Russian Journal of Inorganic Chemistry, 43, 302-305.

[5] Zubkov, S.V. and Shafranskii, I.I. (1979) Russian Journal of General Chemistry, 49, 428.

[6] Aitken, D.J., Albinati, A., Husson, H.-P., Morgant, G., Nguyen-Huy, D., Kozelka, J., Lemoine, P., Ongeri, S., Rizzato, S. and Viossat, B. (2007) Platinum(II) and Palladium(II) Complexes with N-Aminoguanidine. European Journal of Inorganic Chemistry, 21, 3327-3334. http://dx.doi.org/10.1002/ejic.200600998

[7] Chandra, S. and Sharma, A.K. (2009) Antifungal and Spectral Studies of Cr(III) and Mn(II) Complexes Derived from 3, 3’-Thiodipropionic Acid Derivative. Research Letters in Inorganic Chemistry, 2009, Article ID: 945670. http://dx.doi.org/10.1155/2009/945670

[8] Premkumar, T. and Govindarajan, S. (2002) The Chemistry of Hydrazine Derivatives-Thermal Behavior and Characterisation of Hydrazinium Salts and Metal Hydrazine Complexes of 4,5-Imidazoledicarboxylic Acid. Thermochimica Acta, 386, 35-42. http://dx.doi.org/10.1016/S0040-6031(01)00756-0

[9] Roux, J.A. and Wood, B.E. (1983) Infrared Optical Properties of Solid Monomethyl Hydrazine, $\mathrm{N}_{2} \mathrm{O}_{4}$, and $\mathrm{N}_{2} \mathrm{H}_{4}$ at Cryogenic Temperatures. Optical Society of America, 73, 1181-1188. http://dx.doi.org/10.1364/JOSA.73.001181

[10] Brzyska, W. and Ozga, W. (1996) Preparation and Properties of Y(III) and Lanthanide(III) Complexes with Pyridine2,4-dicarboxylic Acid. Thermochimica Acta, 273, 205-216. http://dx.doi.org/10.1016/0040-6031(95)02393-3 
[11] Karraker, D.G. (1968) Hypersensitive Transitions of Hydrated Neodymium-(III)holmium-(III) and Erbium-(III) Ions. Inorganic Chemistry, 7, 473-479. http://dx.doi.org/10.1021/ic50061a018

[12] Peacock, R.D. (1975) The Intensities of Lanthanide $f \leftrightarrow f$ Transitions. Structure and Bonding, 22, 83-122. http://dx.doi.org/10.1007/BFb0116556

[13] Sinha, S.P. (1965) 2,2'-Dipyridyl Complexes of Rare Earths-II: Reflection Spectra of Nd(III)-bis-(2,2'-dipyridyl) and Nd(III)-bis-(4,4'-dimethyl-2,2'-dipyridyl) Chlorides. Journal of Inorganic and Nuclear Chemistry, 27, 115-118. http://dx.doi.org/10.1016/0022-1902(65)80199-3

[14] Henrie, D.E. and Choppin, G.R. (1968) Environmental Effects on $f$ - $f$ Transitions. II. "Hypersensitivity” in Some Complexes of Trivalent Neodymium. The Journal of Chemical Physics, 49, 477. http://dx.doi.org/10.1063/1.1670099

[15] Premkumar, T. and Govindarajan, S. (2003) Synthesis and Spectroscopic, Thermal, and XRD Studies on Trivalent Lighter Rare-Earth Complexes of 2,3-Pyrazinedicorboxylate with Hydrazinium Cation. Inorganic Chemistry Communications, 6, 1385-1389. http://dx.doi.org/10.1016/j.inoche.2003.08.025

[16] Kuppusamy, K. and Govindarajan, S. (1996) New Trivalent Lanthanide Complexes of Phthalate-Containing Hydra- zinium Cationc Preparation, and Spectral and Thermal Studies. Thermochimica Acta, 279, 143-165. http://dx.doi.org/10.1016/0040-6031(96)90076-3

[17] DcBettencourt, D.A. and Viswanath, S. (2004) Chemical Communications, 1024.

[18] Zhan II, X., Xiao, Z.L. and Zhan, H.H. (2008) Rare Earths, 26, 390.

[19] Zang, Z.H., Okamura, T., Hasegawa, Y., et al. (2005) Syntheses, Structures, and Luminescent and Magnetic Properties of Novel Three-Dimensional Lanthanide Complexes with 1,3,5-Benzenetriacetate. Inorganic Chemistry, 44, 62196227. http://dx.doi.org/10.1021/ic050453a

[20] Allan, J.R., Paton, A.D., Turvey, K., Bowley, H.J. and Gerrard, D.L. (1987) Spectral, Magnetic and Electrical Studies on Complexes of Some First Row Transition Elements with Pyrazinecarboxylic Acid. Inorganica Chimica Acta, 132, 41-47. http://dx.doi.org/10.1016/S0020-1693(00)83988-2 
Scientific Research Publishing (SCIRP) is one of the largest Open Access journal publishers. It is currently publishing more than 200 open access, online, peer-reviewed journals covering a wide range of academic disciplines. SCIRP serves the worldwide academic communities and contributes to the progress and application of science with its publication.

Other selected journals from SCIRP are listed as below. Submit your manuscript to us via either submit@scirp.org or Online Submission Portal.
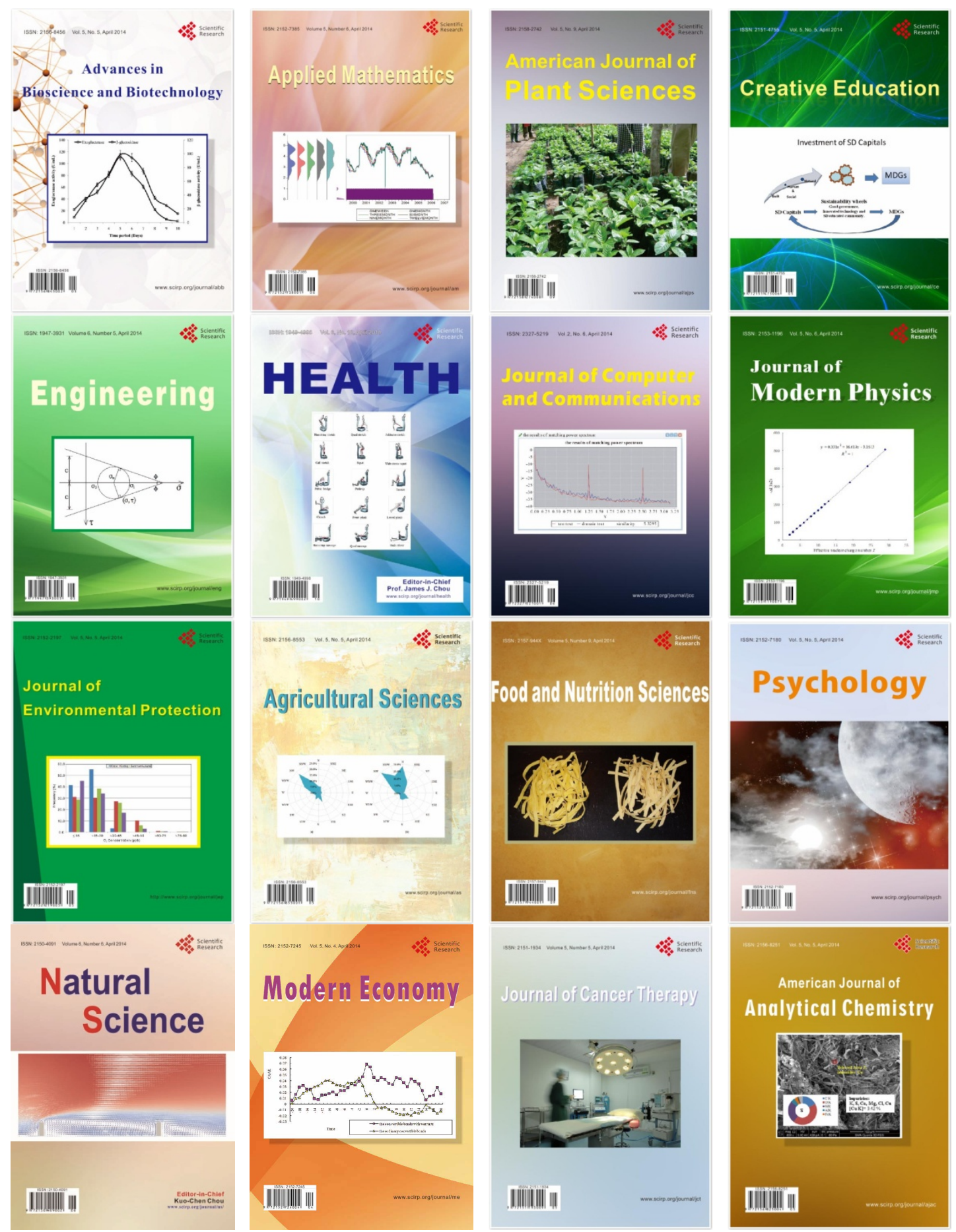